\title{
Growth of beta-silicon carbide whiskers by the VLS process
}

\author{
J. V. MILEWSKI*, F. D. GAC, J. J. PETROVIC, S. R. SKAGGS \\ Los Alamos National Laboratory, Materials Science and Technology Division, \\ PO Box 1663, Los Alamos, NM 87545, USA
}

\begin{abstract}
Beta-silicon carbide whiskers are being grown by a vapour-liquid-solid (VLS) process which produces a very high purity, high strength single crystal fibre about $6 \mu \mathrm{m}$ in diameter and $5-100 \mathrm{~mm}$ long. Details of the growth process are given along with a general explanantion of the effects of the major growth parameters on whisker growth morphology.
\end{abstract}

\section{Introduction}

Whiskers are minute, high purity, single crystal fibres. Inherent with their chemically pure nature and highly ordered structure are strengths that begin to approach interatomic bonding forces. Compared to polycrystalline fibres, they also offer improved resistance to high temperature environments and display greater work-to-fracture. Consequently, there is great interest in utilizing whiskers, particulary silicon carbide (SiC) whiskers, to reinforce and toughen ceramic and glass matrix composites.

Historically, $\mathrm{SiC}$ whiskers have been produced by numerous methods. Knippenberg and Verspui [1] developed a process for producing alpha-SiC whiskers, in which bulk $\mathrm{SiC}$ was vaporized by heating under reduced pressure and the whiskers formed on nucleation sites containing lanthanum or another catalyst. Ryan et al. [2] grew beta$\mathrm{SiC}$ whiskers by the hydrogen reduction of methyltrichlorosilane $\left(\mathrm{CH}_{3} \mathrm{SiCl}_{3}\right)$ onto carbon substrates at $1500^{\circ} \mathrm{C}$. Paratt and co-workers [3] explored the controlled use of combinations of chlorosilanes, carbon monoxide (CO), and methane $\left(\mathrm{CH}_{4}\right)$ as source gases for the production of beta-SiC. Cutler [4] developed a process for producing submicron $\mathrm{SiC}$ powder and whiskers from the silica $\left(\mathrm{SiO}_{2}\right)$ and carbon present in rice hulls. Shyne and Milewski [5] adapted a technique termed the VLS process, first proposed by Wagner and Ellis [6] for the growth of silicon whiskers, to produce beta-SiC whiskers. In addition, Knippenberg et al. $[7,8]$ utilized a VLS process to grow $\mathrm{SiC}$ whiskers. It is the understanding and refinement of the VLS process for $\mathrm{SiC}$ whiskers growth that the present paper addresses.

\section{The VLS process for SiC whisker growth - general}

In the VLS process, V stands for Vapour feed gases, $L$ for Liquid catalyst, and $S$ for Solid crystalline whisker growth. The presence of a liquid catalyst is what distinguishes this method from all other whisker growth techniques. The role of the catalyst is to form a liquid solution interface with the crystalline material to be grown and fed from the vapour through the liquid-vapour interface. The catalyst solution is a preferred site for deposition of feed from the vapour which causes the liquid to become supersaturated. Crystal growth occurs by precipitation from the supersaturated liquid at the solid-liquid interface. In view of this mechanism, catalyst selection is partially based upon the fact that the catalyst must display the affinity, when molten, to take into solution the constituent atoms of the whisker one wishes to grow. For $\mathrm{SiC}$ whisker growth, transition metals and iron alloys satisfy this requirement.

Fig. 1 illustrates a conceivable sequence for the VLS growth of SiC whiskers. At $\sim 1400^{\circ} \mathrm{C}$ the solid catalyst particle melts and forms the liquid catalyst ball. Carbon and silicon atoms in the

\footnotetext{
*Present address: Consultant, 156 Monte Rey Drive, Los Alamos, NM 87544, USA.
} 


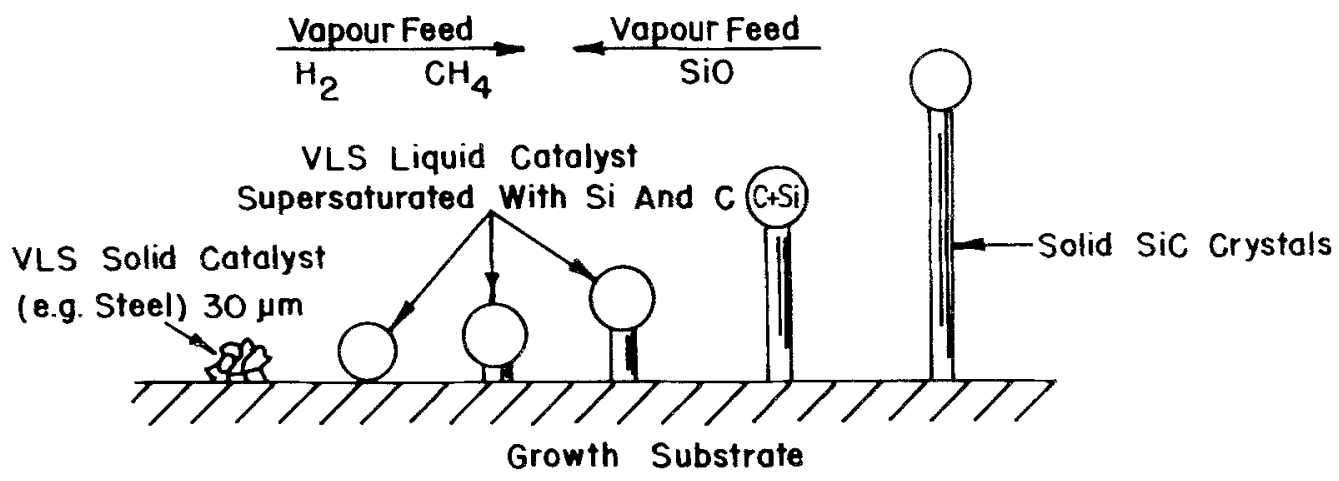

Figure 1 Illustration of the VLS process for SiC whisker growth.

vapour feed are accreted to the surface by the liquid catalyst, which soon becomes supersaturated, and solid $\mathrm{SiC}$ precipitates from the liquid catalyst onto the growth substrate. As precipitation continues, the whisker grows, lifting the catalyst ball from the substrate and forming a whisker which is proportional in size to the catalyst ball. This concept is illustrated by the growth of the fine crystalline rods as shown in Fig. 2.

\section{The Los Alamos process}

3.1. Reactor design and operation

In the Los Alamos process, the $\mathrm{SiC}$ whiskers are grown on parallel plates of graphite that have been previously coated with a uniform dispersion of controlled-size catalyst particles (e.g. $30 \mu \mathrm{m}$ type 304 stainless steel). These plates are placed in a graphite reactor that contains a gas manifold for the uniform distribution of the methane-hydrogen

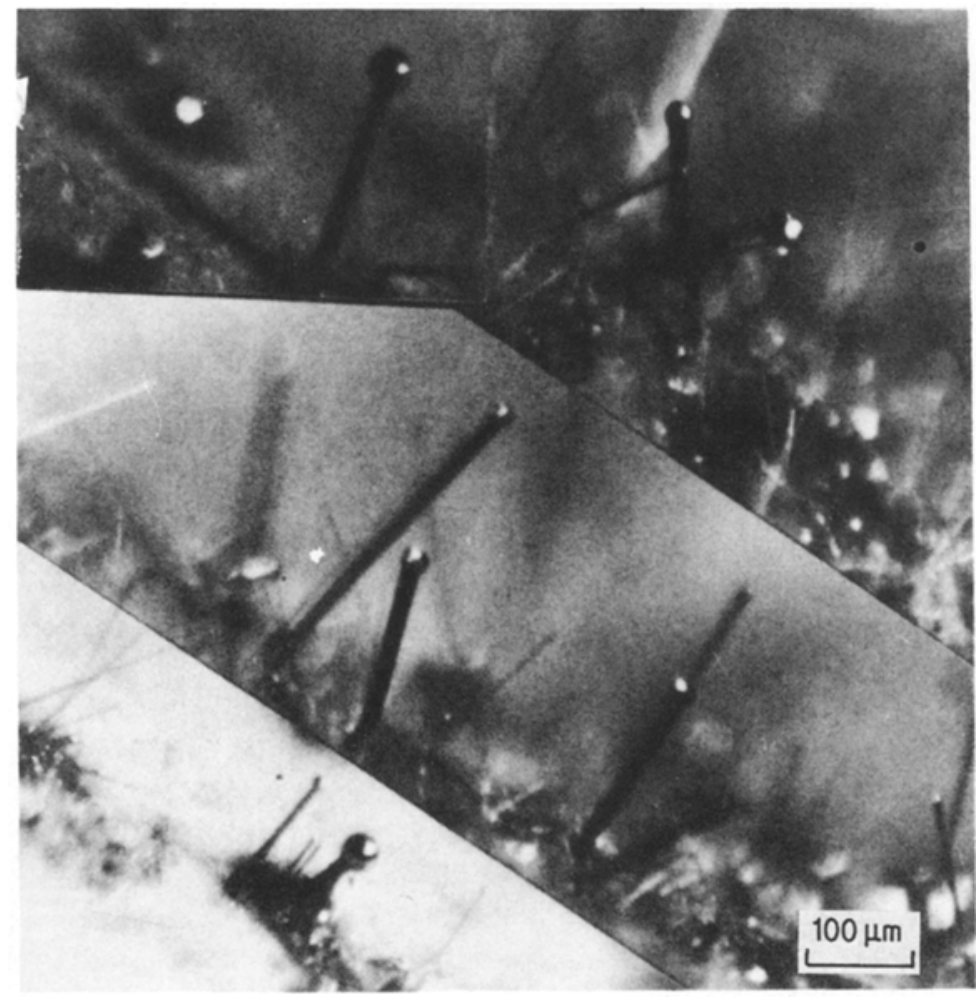

Figure 2 Optical photomicrograph of VLS grown SiC whiskers with metal catalyst ball in place $(\sim \times 150)$. 


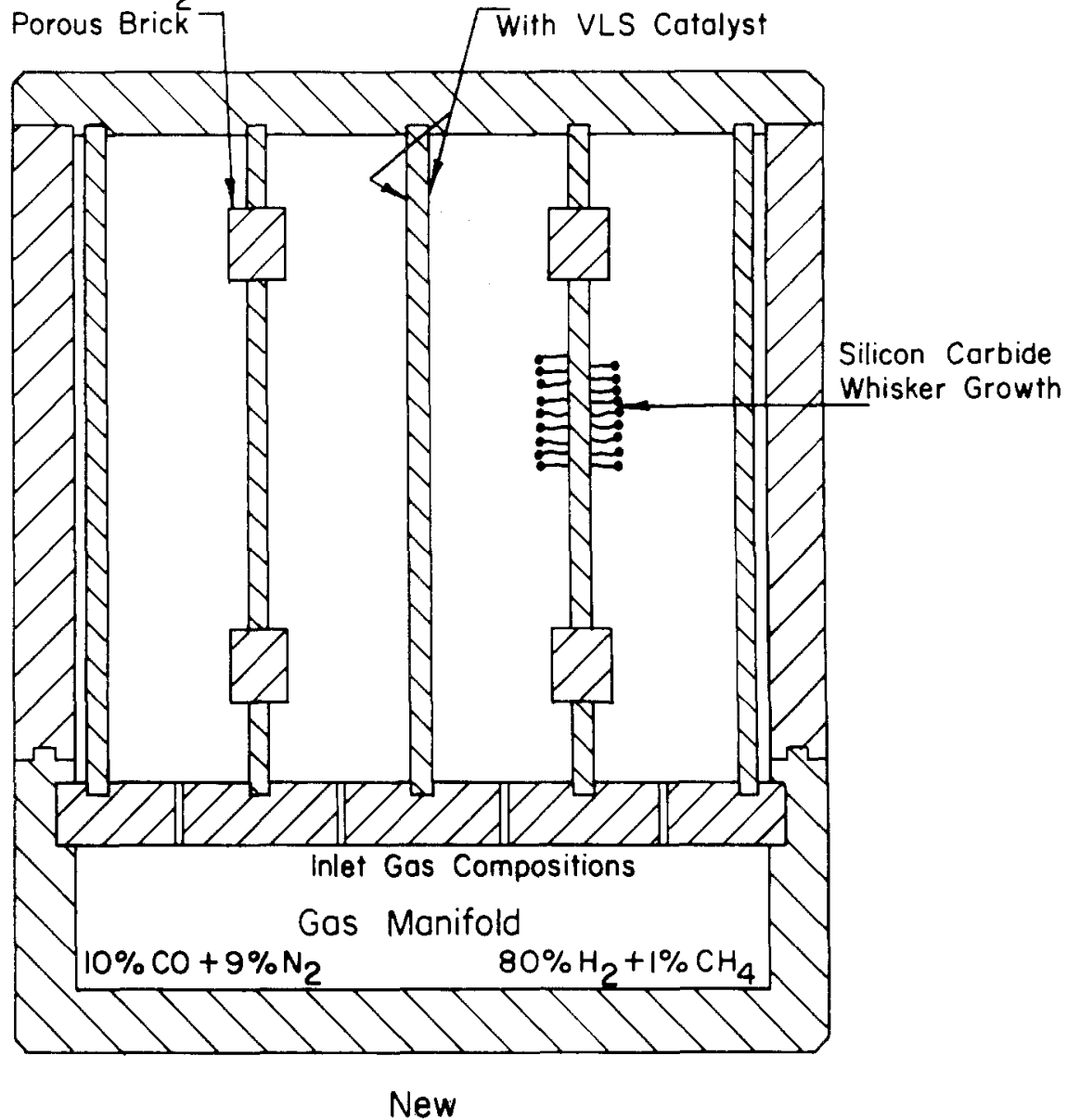

8 Generator. Design

Figure 3 Cross-sectional view of whisker growth reactor.

$\left(\mathrm{CH}_{4}-\mathrm{H}_{2}\right)$ gases. The silicon monoxide $(\mathrm{SiO})$ is generated by the following reaction:

$$
\mathrm{SiO}_{2(\mathrm{~s})}+\mathrm{C}_{(\mathrm{s})} \rightarrow \mathrm{SiO}_{(\mathrm{g})}+\mathrm{CO}_{(\mathrm{g})}
$$

This is accomplished by placing sections of porous insulation brick, which have been impregnated with a fine powder mixture of silica and carbon, into the reactor. To moderate and control the rate of release of the $\mathrm{SiO}, \mathrm{CO}$ is added to the reactor feed gases. Nitrogen $\left(\mathrm{N}_{2}\right)$ gas is added to control the reactive gaseous species' supersaturated level, and "stimulate" the VLS reaction. Fig. 3 shows the design of a whisker growth reactor in cross section. This reactor is $165 \mathrm{~mm}$ wide by $184 \mathrm{~mm}$ tall and is $508 \mathrm{~mm}$ long. The $\mathrm{CH}_{4}$ gas is carried into the reactor through the bottom gas manifold, diluted to about $1 \%$ by $80 \% \mathrm{H}_{2}, 10 \% \mathrm{CO}$, and $9 \% \mathrm{~N}_{2}$. The number and size of the holes in the reactor have been designed to give a uniform flow distribution in the growth chamber. The $\mathrm{SiO}$ gas is generated inside the reactor by $\mathrm{SiO}$ generators distributed throughout the growth plates. The whole reactor is preheated, slipped into a large rectangular quartz tube furnace, and then heated to $1400^{\circ} \mathrm{C}$ for approximately $10 \mathrm{~h}$. During this period, whisker growth is initiated with growth of $10-20 \mathrm{~mm}$ lengths. The carbonaceous gas enters the reaction chamber from the bottom manifold and mixes with the $\mathrm{SiO}$ gas. The $\mathrm{SiO}$ and $\mathrm{CH}_{4}$ react with the catalyst in a presently unidentified fashion, the catalyst solution becomes supersaturated in carbon and silicon, and a $\mathrm{SiC}$ crystal precipitates on the growth substrate. The spent gases are vented out of the top of the growth chamber, through the muffle to the outside of the furnace hot zone and are burned off. 


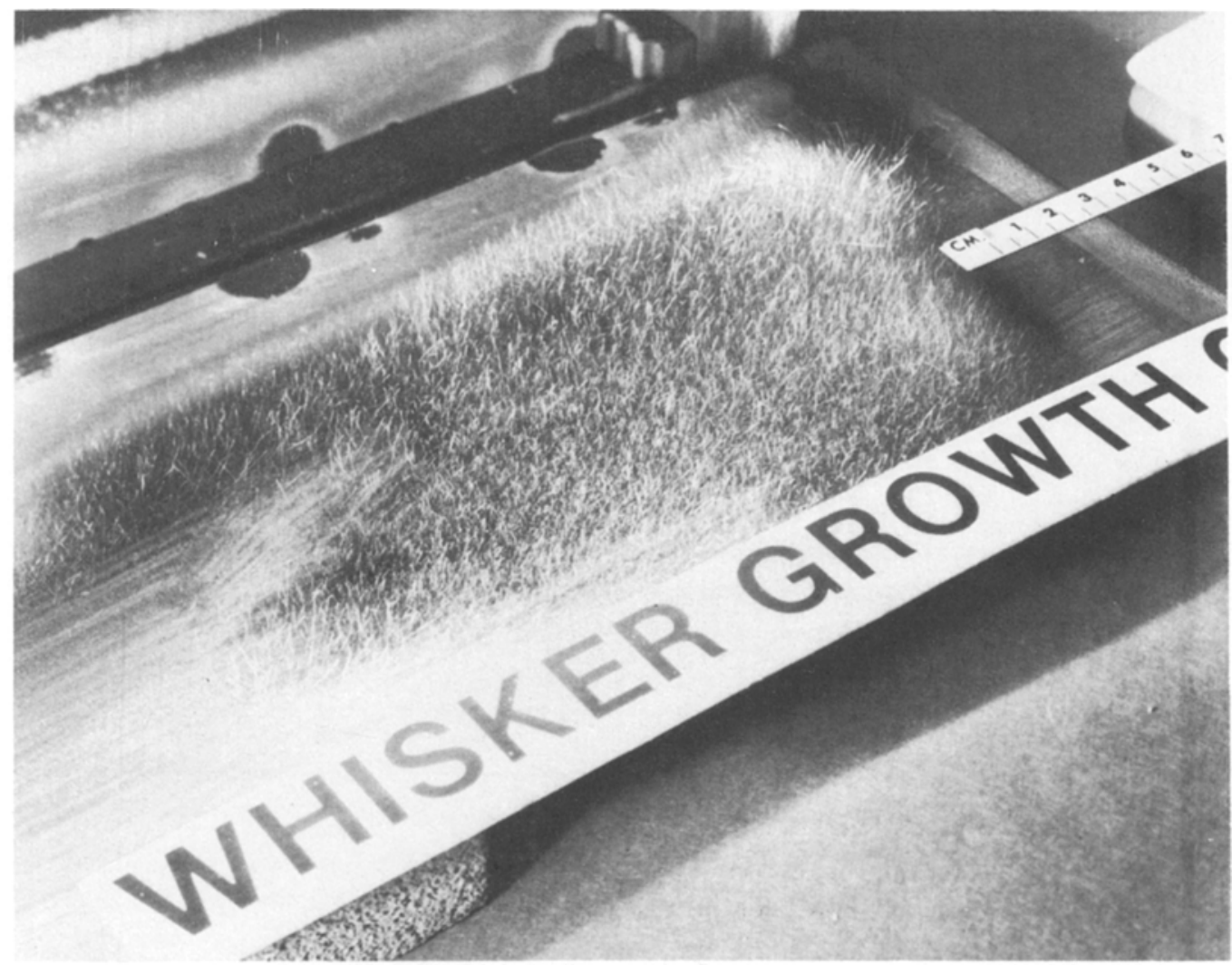

Figure 4 Field of SiC whisker growth.

After the run is over, the furnace is cooled to $800^{\circ} \mathrm{C}$ and the whole reactor is taken out of the furnace. The reactor must then be cooled to room temperature before it can be disassembled to extract the whisker yield. Fig. 4 shows a close up of the whiskers growing like a field of grass on the reactor growth plates. Finally, the whiskers are harvested from the plates and the various grades are separated, classified, and cleaned before further use.

\subsection{Product identification}

To clearly identify the various types of whisker growth, a standard identification code for $\mathrm{SiC}$ whisker growth has been established. This code is charted in Fig. 5. Twenty-four categories have been allocated to identify the various types of growth produced in our process. These categories represent a matrix of four degrees of gas phase supersaturation (rows A, B, C, D) and six degrees of gas phase stoichiometry (columns 1, 2, 3, 4, 5 and 6).

The growth changes that occur as one increases the degree of supersaturation can be explained as follows. Below row A, the supersaturation is too low to support whisker growth. At level A, the large 4 to $8 \mu \mathrm{m}$ diameter needie type growth is initiated. This is the lowest level of supersaturation that will support whisker growth with a VLS catalyst. Fig. 6 shows type $5 \mathrm{~A} \mathrm{SiC}$ whisker growth. $\mathrm{X}$-ray diffraction (XRD) confirms these whiskers to be pure beta-SiC growth in the $\langle 111\rangle$ direction. They display a smooth surface and a roundedtriangular cross section, as shown in Fig. 7. As one proceeds to a higher degree of supersaturation, row $\mathrm{B}$, minute multiple growth sites are activated on the substrate, in preference to the VLS catalyst, and many smaller 1 to $3 \mu \mathrm{m}$ diameter whiskers are grown. Fig. 8 shows type $4 \mathrm{~B} \mathrm{SiC}$ whisker growth, which XRD analysis shows to be a mixture of betaand alpha-SiC. At conditions in row $\mathrm{C}$, the excess supersaturation is sufficient to activate secondary growth sites on the sides of the whisker, causing very small 0.5 to $1.0 \mu$ m diameter side branches to occur. At row $\mathrm{D}$ the supersaturation is so high that essentially all growth is the side branch type, grown tightly into small fibrous clusters, as shown in Figs. 9 and 10 for type 6D whiskers. 


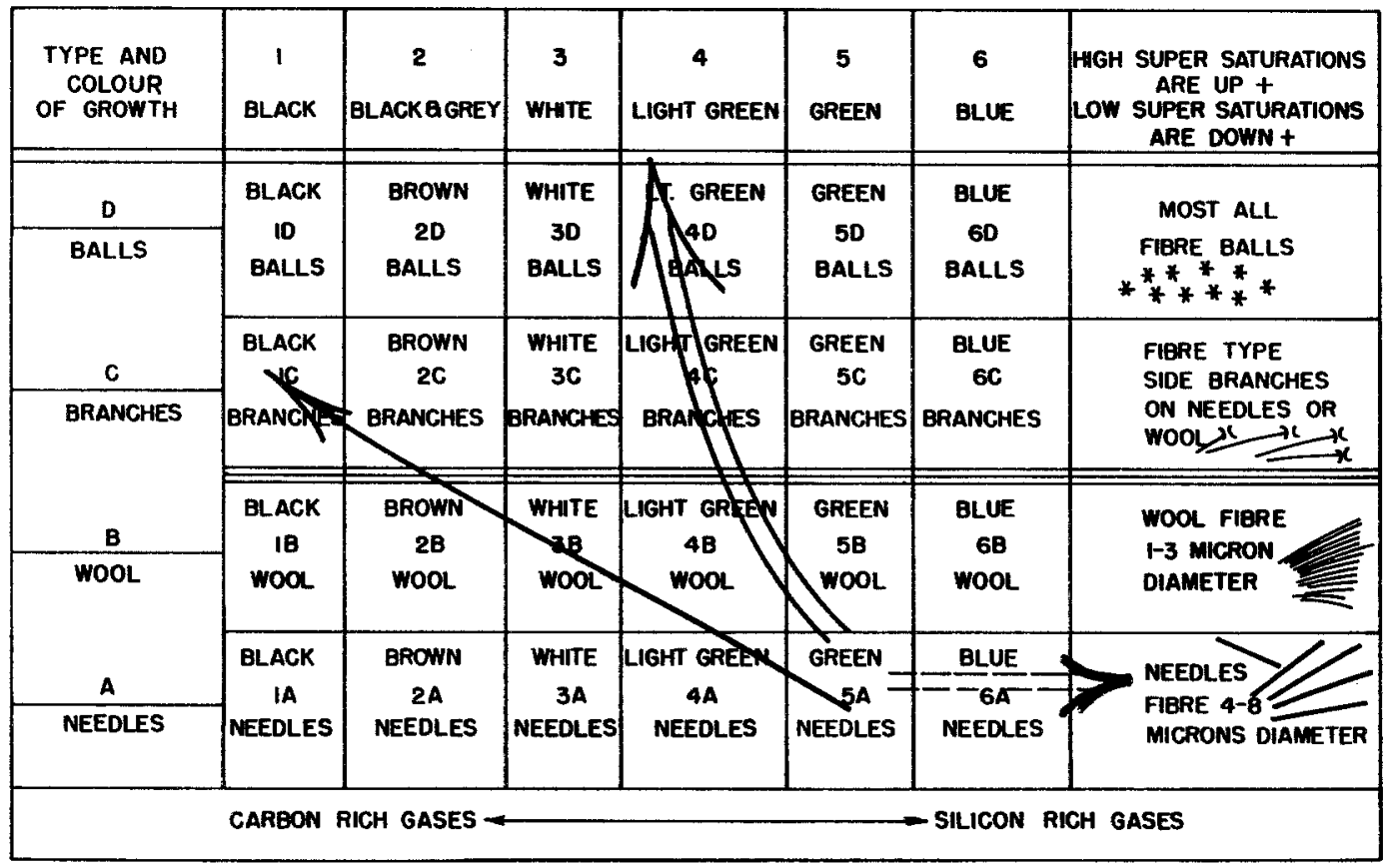

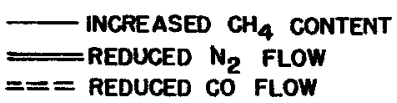

Figure 5 Identification chart for $\mathrm{SiC}$ whisker growth conditions.

Examining the change that occurs as one goes from carbon rich to silicon rich stoichiometry, one finds on the carbon rich side, column 1, that the $\mathrm{SiC}$ whisker growth colour is black due to excessive carbon deposits on the whisker. Column 2 has less carbon deposits and this produces brown and dark grey coated whiskers. Column 3 may be stoichiometrically perfect since pure white silicon carbide whiskers are produced. As the gases become more silicon rich, the $\mathrm{SiC}$ whiskers take on a light green colour at column 4 , possibly due to

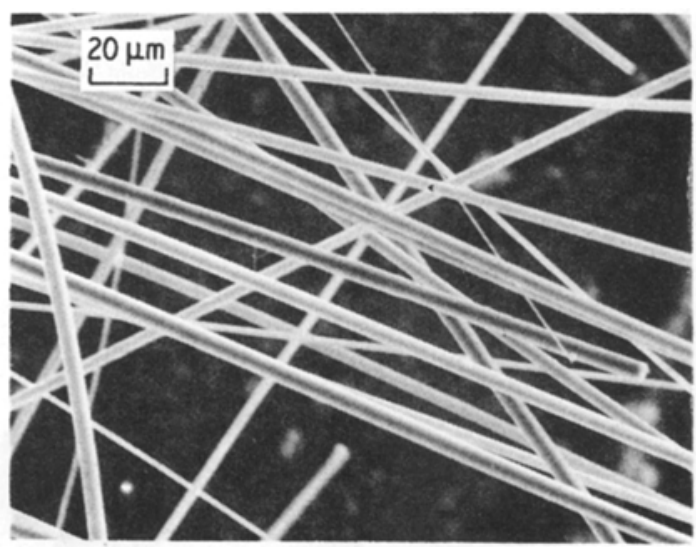

Figure 6 Type 5A SiC whiskers $(\times 500)$. nitrogen doping which occurs in silicon rich atmospheres. In column 5 the whiskers exhibit a darker emerald green colour. At an even more silicon rich positions in column 6 , blue $\mathrm{SiC}$ whiskers are produced.

\subsection{Control of growth types}

By controlling the gas phase composition and the degree of supersaturation, significant control can be exercised over the growth of $\mathrm{SiC}$ whiskers. For example, if one looks at the identification chart

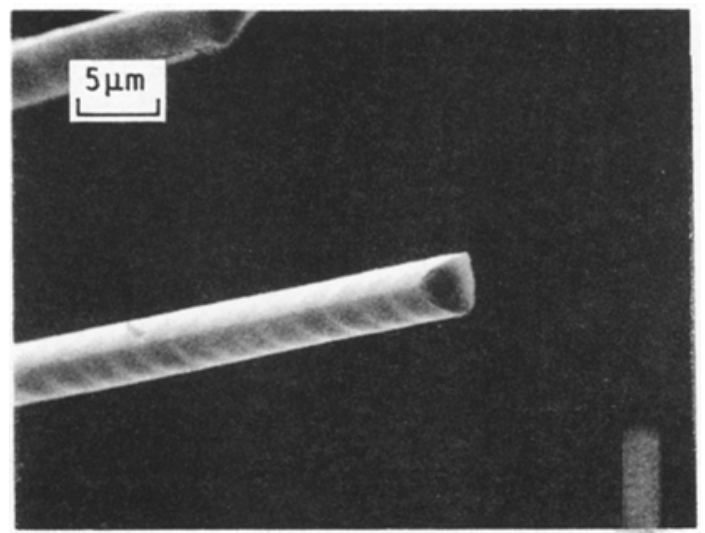

Figure 7 Close-up of beta-SiC whisker (type 5A), showing rounded-triangular cross section $(\times 3000)$. 


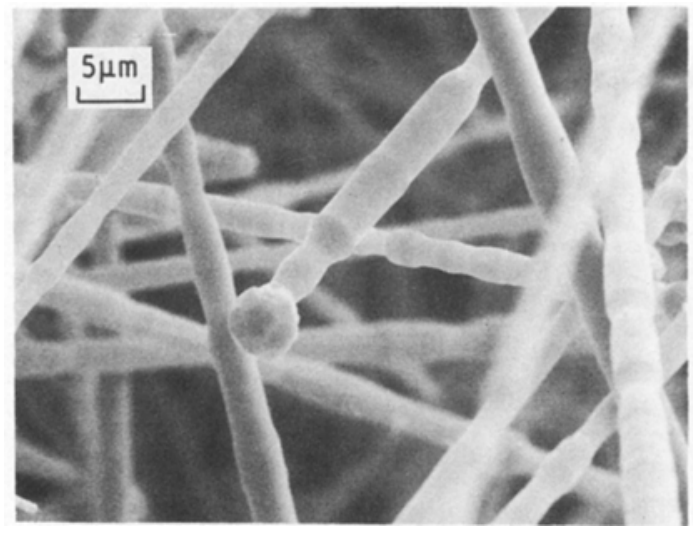

Figure 8 Type $4 \mathrm{~B}$ SiC whiskers ( $\times 2500)$.

(Fig. 5) where the growth conditions are such as to produce whiskers of type $5 \mathrm{~A}$ (e.g. $\sim 80 \% \mathrm{H}_{2}, 10 \%$ $\mathrm{CO}, 9 \% \mathrm{~N}_{2}, 0.5 \% \mathrm{CH}_{4}, 0.5 \% \mathrm{SiO}$ at $1400^{\circ} \mathrm{C}$, using $25 \mu \mathrm{m}$ diameter stainless steel catalyst), one can predict how the growth will change by reducing the $\mathrm{CO}$ gas flow by half. This would increase the generation of $\mathrm{SiO}$ and shift the growth from $5 \mathrm{~A}$ to $6 \mathrm{~A}$, and off the chart if the $\mathrm{CO}$ is turned off completely. This occurs because $\mathrm{CO}$ is used as a moderator to control the generation of $\mathrm{SiO}$ as indicated by Equation 1 . To produce $5 \mathrm{~A}$ type growth, the $\mathrm{SiO}$ generation is suppressed by the addition of $\mathrm{CO}$ gas. Consequently, when that gas is taken away the $\mathrm{SiO}$ is produced too fast and even in excess of that required for optimum $5 \mathrm{~A}$ whisker growth.

Another question that can be asked is how is growth affected when $\mathrm{N}_{2}$ gas is reduced? Nitrogen

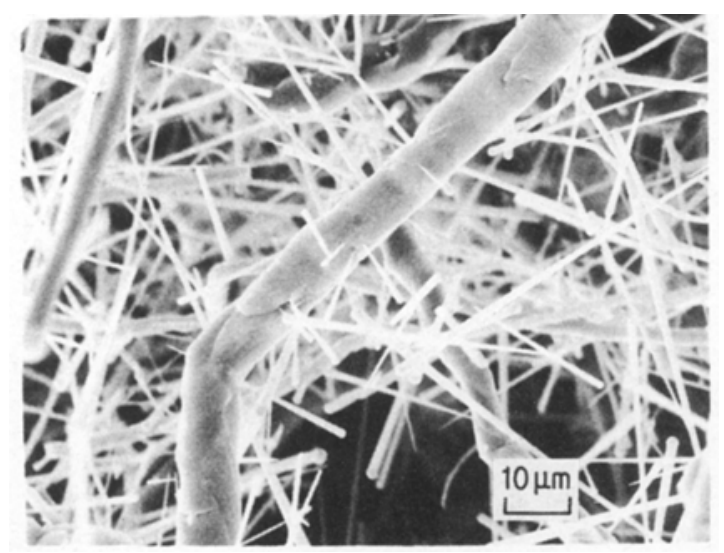

Figure 9 Type 6D SiC whiskers $(\times 1000)$.

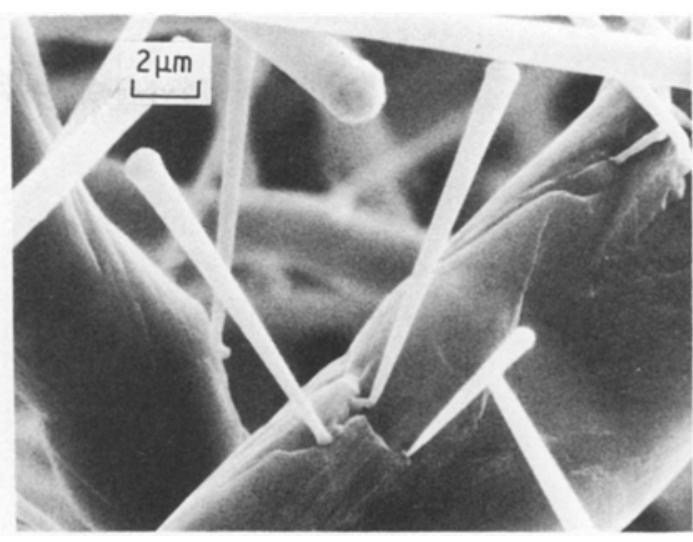

Figure 10 Close up of type 6D SiC whisker showing branch growth nucleating from growth defects in large whisker ( $\times 5000)$.

acts as a diluent reducing all supersaturation levels and also acts as a stimulant to the VLS catalyst, possibly by changing liquid-solid interfacial energies. When its concentration is halved, the whisker growth morphology becomes finer and less green ( $5 \mathrm{~A}$ to $4 \mathrm{~B}$ ), and when the $\mathrm{N}_{2}$ gas flow is eliminated completely the growth changes to type $3 \mathrm{C}$ and $3 \mathrm{D}$ whisker morphology.

The effect of changes in $\mathrm{CH}_{4}$ gas flow proceed exactly as one would expect. If no $\mathrm{CH}_{4}$ is introduced, no $\mathrm{SiC}$ whisker growth occurs. As the $\mathrm{CH}_{4}$ is increased, more carbon is introduced into the catalyst, producing a progression of $5 \mathrm{~A} \rightarrow 4 \mathrm{~B} \rightarrow$ $3 \mathrm{~B} \rightarrow 2 \mathrm{C} \rightarrow 1 \mathrm{C}$ whisker growth types.

\section{Whisker purity and mechanical properties}

The chemical analysis of type $5 \mathrm{~A}$ and $6 \mathrm{~A}$ whiskers, determined by emission spectroscopy, is shown in Table I. Also shown for comparison is the chemical analysis (determined at Los Alamos) for $\mathrm{SiC}$ whiskers produced by ARCO Metals-Silag Operation*, Tateho Chemical Industries $\dagger$, and Tokai Carbon Co Ltd $¥$. The major impurity in Los Alamos SiC whiskers is aluminium, with sodium, magnesium, calcium and iron also present to a lesser degree. The most likely sources of some of these impurities are the graphite reaction chamber and growth substrates, and the alumino--silicate insulation brick used in the $\mathrm{SiO}$ generation scheme.

The mechanical properties of the whiskers are

\footnotetext{
*Formerly Exxon Enterprises Inc, Silag Div; now ARCO Metals Company, Silag Operation, Greer, SC 29651.

TDistributed in the US by Mitsubishi International Corporation, New York, NY 10172.

¥Tokamax SiC whiskers; also distributed by Mitsubishi International.
} 
TABLE I Silicon carbide whisker chemistry (weight ppm)

\begin{tabular}{lrrlr}
\hline Element & Los Alamos & Silag & Tateho & Tokai \\
\hline $\mathrm{Na}$ & $<100$ & 150 & - & 400 \\
$\mathrm{Mg}$ & 120 & 1000 & 1500 & 50 \\
$\mathrm{Al}$ & 800 & 2000 & 600 & 600 \\
$\mathrm{~K}$ & $<300$ & 300 & - & $<300$ \\
$\mathrm{Cu}$ & 400 & 4000 & 3800 & 30 \\
$\mathrm{Ti}$ & 30 & 200 & - & 150 \\
$\mathrm{Cr}$ & 20 & 150 & - & 200 \\
$\mathrm{Mn}$ & 25 & 800 & - & 15 \\
$\mathrm{Fe}$ & 150 & 2000 & 10 & 1000 \\
$\mathrm{Ni}$ & 50 & 150 & - & 150 \\
Total & 1995 & 10750 & 5910 & 2895 \\
\hline
\end{tabular}

reported in another aritcle by Petrovic et al. [9]. In that article, the authors point out that whiskers measuring 5-6 $\mathrm{m}$ in diameter and $5 \mathrm{~mm}$ in length display an average tensile strength of $8.4 \mathrm{GPa}$ and an average elastic modulus of $581 \mathrm{GPa}$.

\section{Concluding remarks}

Los Alamos has improved the VLS process for producing $\mathrm{SiC}$ whiskers. A better understanding of the overall process has been obtained. The major effects of various gas compositions on whisker growth were determined. The full range of growth morphologies has been identified and charted in relation to the degree of supersaturation and stoichiometry of the gases.

\section{Acknowledgements}

The authors gratefully acknowledge support from the Office of Advanced Research and Technology
Development, Fossil Energy Materials Program, US Department of Energy. The services of the following are greatly appreciated: P. D. DeVargas; L. B. Edgett; J. T. Hunter and R. D. Blake for whisker growth and processing; R. B. Roof and S. C. Stotlar for X-ray diffraction analysis; C. A. Javorsky and J.R. Bradberry for SEM analysis, D. G. Vigil for typing the manuscript; G. F. Hurley for helpful technical comments; and J.W. Booth for editorial assistance.

\section{References}

1. W. F. KNIPPENBERG and G. VERSPUI, "Silicon Carbide - 1972" edited by R. C. Marshall, J.W. Faust Jr and C. E. Ryan (University of South Carolina Press, 1973) p. 108.

2. C. E. RYAN, I. BERMAN, R. C. MARSHALL, D. P. CONSIDINE and J. J. HAWLEY, J. Crystal Growth, 1 (1967) 255.

3. N. J. PARRATT, "Fibre Reinforced Materials Technology" (Van Nostrand Reinhold, London, 1972).

4. I. B. CUTLER, "Production of Silicon Carbide From Rice Hulls" US Patent 3754 076, August 1973.

5. J. J.SHYNE and J. V. MILEWSKI, "Method of Growing Silicon Carbide Whiskers" US Patent 3622 272, November 1971.

6. R. S. WAGNER and W. C. ELLIS, Appl. Phys. Lett. 4 (1964) 39.

7. W. F. KNIPPENBERG and G. VERSPUI, Mater. Res. Bull. 4 (1969) 33.

8. G. A. BOOTSMA, W. F. KNIPPENBERG and G. VERSPUI, J. Crystal Growth 11 (1971) 297.

9. J. J. PETROVIC, J. V. MILEWSKI, D. L. ROHR and F. D. GAC, J. Mater. Sci. 20 (1985) 1167.

Received 29 May

and accepted 3 July 1984 